\title{
Analysis of Construction Technology Improvements based on the Energy Saving Requirements
}

\author{
Siyi Wang ${ }^{1, a}$ \\ ${ }^{1}$ Xi an Siyuan University, Xi’an, Shaanxi, China, 710038 \\ a email
}

Keywords: Analysis, Construction Technology, Improvements, Energy Saving Requirements

\begin{abstract}
The construction industry is one of the pillar industries of modernization, the development of the construction industry largely contributed to the development of the national economy, but at the same time, it also brings great energy consumption. Compared with other engineering purposes, construction engineering has such features such as many construction materials, long construction period and construction technology is complex. The energy consumption is mainly concentrated in the construction phase and the article analyzes the improvement measures of building construction technology.
\end{abstract}

\section{Introduction}

With the development of energy-saving technology, science and technology and vigorously promote the technology, making energy conservation become the era of the construction industry and the development direction of the theme, Building Construction vigorous use of energy-saving technologies, development of new energy and renewable energy saving, use energy-saving and environmental protection building materials, thus effectively reducing the energy consumption of the building construction, resources, construction materials, saving limited shortage of conventional energy sources and non-renewable resources, reducing pollution of air, water and other natural environmental pollutants or harmful substances emissions, thus contributing to the construction technology continues to improve, which will help the construction industry to sustainable development.

\section{The Basic Content of Energy Saving}

The so-called energy-saving means to reduce energy consumption as much as possible to produce the same quality as the original, the same quantity of products, or in the original production of the same amount of energy consumption of products used to produce more than the original amount, or an equal number of quality better products. According to the World Energy Council in 1979 he proposed saving meaning that the energy connotation refers to take technically feasible, economically rational, environmental and socially acceptable, and effective measures to all energy-saving technologies to improve energy resources use efficiency of innovative ideas, where technically feasible means can be implemented on the basis of prior art, operable; economically justified is the ratio of inputs and outputs to fit properly; environmentally acceptable means any energy-saving technology measures to protect the environment, meet environmental requirements, reduce environmental pollution; and social acceptance means accepting energy saving technology does not affect the normal production and social improvement of people's living standards; energy effectiveness is simply more to reduce loss and waste of energy resources. And on the economic production, technology management, energy conservation is to take practical and effective energy-saving technical measures to effectively reduce energy production, energy consumption and other aspects of loss and waste, scientific and rational use of energy resources, reduce carbon dioxide emissions pollute the environment. In short, energy is China's basic national policy, is a long-term strategy of sustainable economic development, and therefore, in many areas of the construction industry should pay attention to energy conservation and environmental protection, in order to gain economic benefits, social benefits and ecological balance environmental benefits. 


\section{The Overview of Building Energy-Saving Construction Technology}

EEB is a kind of energy-saving technology-based, interdisciplinary, cross-sector urban planning, architecture and civil engineering, equipment, electrical and mechanical expertise and materials, environment, energy, expertise in electronics, information and ecological engineering. Building energy-saving technology is based on the requirements of energy-saving technologies and skills policy requirements mainly to reflect on the concept of sustainable development as a guide to energy-saving technology as the center of modern and advanced technology. Building energy-saving technology compared with traditional construction technology, has the following advantages: First, the goal of building construction technology, the traditional construction technology and engineering quality and pay more attention to the construction period, and pay more attention to building energy-saving technology Low energy consumption to meet the building performance and a high degree of comfort; second, the traditional construction technology to maximize the economic benefits of more attention to construction projects, and building energy-saving technologies on the basis of maximizing the economic benefits, pay more attention to social benefits ecological balance and environmental benefits, namely at the lowest cost of environmental pollution in exchange for economic benefits; third, construction technology building energy efficiency considering the coordination of economic development and the environment, pay attention to environmental protection, combined with the local climate, resources and so on to make architectural design style diversity, ecological; fourth, building energy-saving technologies can be recycled building materials, full use of energy resources, natural resources and material resources, but also the use of energy-saving technologies to improve the quality of construction projects, reducing energy resources consumption, reduction of resources, energy, and waste material loss.

\section{The Problems in Construction Improvements Technology based on the Energy Requirements}

In recent years, with the promotion of energy-saving technologies and in-depth development, as well as policies on energy conservation, environmental protection and other countries have enacted such that the construction industry has recognized the importance of improved energy-saving construction technology, construction technology building strong the application of energy-saving technologies, and achieved remarkable results, so that the construction industry in the construction process not only effectively reduce energy and resource consumption, improve the technological level and the construction quality of construction, but also to achieve the pollution emission standards, but in the construction of energy-saving technology there are still some problems in the process of improvement, promotion and implementation of energy-saving effect of building technologies, is not conducive to the progress of building construction technology.

With the construction of the waste of energy and other issues become more apparent, the state began to develop a series of policies to support the reform and construction of energy-saving issues. Some cities and large construction companies, and actively respond to national call, improvement of energy-saving construction and exploration, and achieved good success, so that the construction of green, energy-saving direction. Of course, this is gratifying, but the scope of the impact of energy-saving building construction is not comprehensive.

Energy-efficient construction, and not rely solely on planning policy and advocacy, or construction management of the country, which requires everyone to actively participate and keep energy awareness and self-restraint, but now a lot of on-site construction workers, still there is a casual construction The phenomenon. For water and power resources, can not be good way to save, after water, electricity is not timely completed Shut off water, power, resulting in a waste of water and power resources, but not good management of water and power resources, but also has a certain risk of endangering the safety of construction workers. For the scene of wanton destruction of vegetation, soil erosion leading to increased rain, resulting in waste of land resources, but also lead to increased dust, increased pollution of the environment. For the random destruction of finished products, finished products and waste lead to failure, increased input of resources and so on. In addition, there are many on-site construction of arbitrariness caused by waste, and waste of these 
energy-saving constructions is out of tune, and it is an urgent problem.

For the energy requirements under construction, management and technical staff plays a very important role. Reasonable planning and construction technology deployment is to ensure the smooth construction of the premise, but also for energy savings of great significance. Thought of management and technical personnel of energy-saving construction, usually reflected in the technical planning and construction deploy them in good progress of the project to achieve energy savings at the same time, it is one of the responsibilities of managers and technical staff. But many managers or technical staff of energy-saving construction of ideology is weak, which directly affects the construction of energy efficient buildings. In addition, strong technical staff capacity is not enough, consider not comprehensive plan for the construction, may lead to disjointed construction, resulting in rework and so on, has been completed for the construction or re-construction destruction, etc., will increase the waste of energy. Therefore, management and technical staff lack of capacity, the energy requirements for the improvement of the same building under construction technique is disadvantageous.

New building materials, the development and use of construction techniques, construction for improved energy efficiency will play a big role, of course, China in recent years for exploration and development of the construction industry are increasingly concerned, and the pace of development has never stop. Although in recent years for new technology, materials research and development of breakthrough and there is a certain contribution, but more change of materials, technology and equipment are also still lacking.

\section{The Sense of the Building Construction based on the Energy Requirements}

Booming construction industry is an important manifestation of social progress, the modernization process is inseparable from the construction, but construction has not completely adapted to modern society. For the construction of the existence of energy waste, the construction industry has been rising since the existence of ills. Due to the construction of their own characteristics, not like construction and other industries, to achieve rapid transformation and change, but it does not mean that the construction does not require energy-saving improvements. Improved energy efficiency in building construction is urgent, based on energy-saving construction technology under, so that construction can better respond to the slogan of sustainable development. The construction industry is a very large energy-consuming industries and so do energy-saving building construction for energy conservation and environmental protection is very meaningful. Energy conservation is not just to save resources, but also a direct impact on pollution and environmental protection issues, for example, in the construction of water recycling, waste water can be reduced, which is important for the protection of the environment, We will also be able to better adapt to China's sustainable development policy, so that the construction industry has gradually become a green and sustainable development of the industry.

\section{The Improved Method of Construction Technology under the Energy-Saving Requirements}

Based on the important role of energy-saving construction techniques improved and the inevitable trend in the energy efficiency requirements under construction buildings technology improvements, specific improvement methods in the following areas:

The Use of the Water-Saving Technologies. Since the construction works of water is relatively large, and therefore the use of energy-saving technologies in the construction of water saving technologies such reduced consumption and save water resources. The construction of concrete mixing and post the largest water conservation work, but also prone to water wastage and losses and, therefore, when the concrete mixing stage use water-saving technologies, strengthen inspection of water pipelines and water supply systems and maintenance avoiding the pipeline rupture, water loss, thereby saving water resources construction needs and ensure the smooth progress and quality of construction work.

The Technology of Using Solar, Wind and Other New Energy Sources. After a lot of 
construction engineering examples prove that solar, wind and other new energy in China is currently the use of technology is relatively mature, clean energy environmental green new energy, in which the use of solar energy is reflected in the promotion and widespread use of solar water heaters and solar cells, the solar water heater is placed on the roof of the house without taking up space, and by an unlimited amount of solar energy to learn, making residents more convenient; comfortable while vigorously develop the use of solar energy also saves the state of the coal, oil, electricity and other energy resources; the application of wind energy can generate electricity for the construction of electricity, thereby easing the power shortage in the country the status quo.

The Use of Energy-Saving Building Materials, Energy Conservation and Reduce Environmental Pollution. In the wall materials in building materials to choose energy-saving insulation materials, such as burning products wall materials, wall materials and wall materials of products autoclaved products are better energy saving materials in the construction has been widely adopted because of wall materials burning products mainly applied to hollow brick, so that relatively large thickness of hollow bricks, hollow bricks to enhance the capacity building, and promoting the successful completion of construction workers, and autoclaved products wall materials the main ingredient is energy saving lime and sand, and low power consumption of lime in the sand, radioactive surrounding environment is low, there is little risk to the environment, in addition to the use of formwork concrete and aerated concrete building walls increases energy-saving materials, insulation, while reducing the energy consumption of building materials.

Strengthen the Staff Management. Construction site staff is the foundation of building construction, natural construction for energy efficiency has a great influence. Strengthen the management of site construction personnel to strengthen their ideological education, and develop appropriate reward and punishment system. On-site construction personnel entering education, training and occasional awareness of energy conservation, from the details of the start, saving water resources, as well as the finished scene vegetation protection; develop appropriate reward and punishment system, to pay attention to energy saving warning ! penalties and other measures, which he served for water flow, finished using the machine is not timely closing mechanical and other acts resolutely put an end; at the same time for the construction process, there is whimsy and energy contribution of staff, encouragement and incentive to mobilize everybody energy-saving initiative, is also conducive to brainstorming, positive significance for the exploration of energy-efficient construction management and staff have.

\section{Conclusion}

In short, we should vigorously use energy-saving construction technology and energy-for environmental building materials, thus reducing the construction of energy resources, building materials consumption, reduced pollutant emissions pollute the environment, energy saving and environmental protection, so as to promote economic efficiency in the construction industry balanced development and to maximize the social and ecological benefits.

\section{References}

[1] Jia Xinzhang, Li Jingyuan. Scientific and Technological Innovation and Application, Vol. 6 (2004) No 53, p.25-26

[2] Peng Sue, Wang Yunhui, Wang Qunyong. Scientific and Technological Innovation, Vol. 12 (2005) No 27, p.74-76

[3] Qian Xiyuan, Jing Jianfen, Hou XuSiem. Doors and Windows, Vol. 30 (2004) No 19, p.144-145

[4] Wang Kuailiang. City Building, Vol. 29 (2008) No 27, p.21-23

[5] Zhang Gongxu, Sun Jing. Theory of Urban Construction, Vol. 8 (2003) No 27, p.57-60 